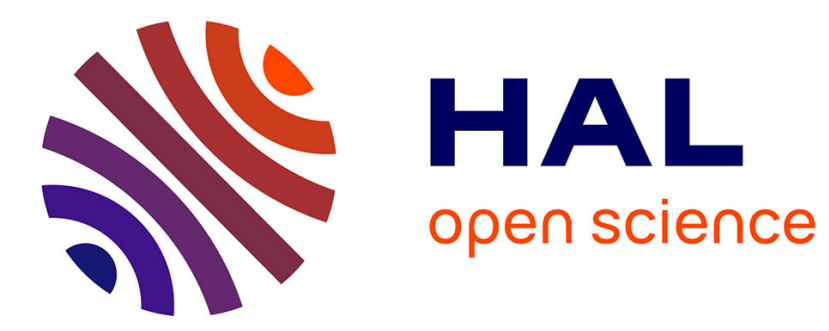

\title{
Water transfer in soil at low water content. Is the local equilibrium assumption still appropriate?
}

Francois Ouedraogo, Fabien Cherblanc, Bétaboalé Naon, Jean-Claude Benet

\section{To cite this version:}

Francois Ouedraogo, Fabien Cherblanc, Bétaboalé Naon, Jean-Claude Benet. Water transfer in soil at low water content. Is the local equilibrium assumption still appropriate?. Journal of Hydrology, 2013, 492, pp.117-124. 10.1016/j.jhydrol.2013.04.004 . hal-00809260

\section{HAL Id: hal-00809260 \\ https://hal.science/hal-00809260}

Submitted on 8 Apr 2013

HAL is a multi-disciplinary open access archive for the deposit and dissemination of scientific research documents, whether they are published or not. The documents may come from teaching and research institutions in France or abroad, or from public or private research centers.
L'archive ouverte pluridisciplinaire HAL, est destinée au dépôt et à la diffusion de documents scientifiques de niveau recherche, publiés ou non, émanant des établissements d'enseignement et de recherche français ou étrangers, des laboratoires publics ou privés. 


\title{
Water transfer in soil at low water content. Is the local equilibrium assumption still appropriate?
}

\author{
F. Ouedraogo ${ }^{\mathrm{a}}$, F. Cherblanc ${ }^{\mathrm{b}, *}$, B. Naon ${ }^{\mathrm{a}}$, J.-C. Bénet $^{\mathrm{b}}$ \\ ${ }^{a}$ GERME \&G TI, Université Polytechnique de Bobo Dioulasso, Burkina Faso \\ ${ }^{b}$ LMGC, CNRS, Université Montpellier 2, Place Eugène Bataillon \\ 34000 Montpellier, France
}

\begin{abstract}
The dynamics of water content in the superficial layers of soils is critical in the modelling of land-surface processes. In arid regions, vapour flux contributes significantly to the global water mass balance. To account for it in theoretical descriptions, most of the models proposed in the literature rely on the local equilibrium assumption that constrains the vapour pressure to remain at its equilibrium value. It implicitly amounts to consider an instantaneous phase change. Recent works underlined a retardation time and a decrease in phase change rate as the water content gets lower. Therefore, the objective is to revisit water transport modelling by rejecting the local equilibrium assumption. This requires developing a non-equilibrium model by taking into account the phase change kinetics. To assess the interest of this approach, a natural soil of Burkina-Faso has been experimentally characterized from independent tests and soil column experiments have been carried out. The comparison of experimental drying kinetics and water content pro-
\end{abstract}

\footnotetext{
*Corresponding author - E-mail: fabien.cherblanc@univ-montp2.fr - Tel: (+33) 467149-639 - Fax: (+33) 467-144-555
} 
files with computational predictions confirms the reliability of this description. Liquid/gas non-equilibrium is significant in a limited subsurface zone which defines explicitly the transition from liquid transport in lower layers to vapour transport in upper layers, i.e., the evaporation front. The overall moisture dynamics is governed by the coupling between water transport mechanisms (liquid filtration, vapour diffusion, phase change) that mainly occurs in this transition zone.

Keywords: water transport, evaporation, non-equilibrium, experimental, modelling

\section{Introduction}

Land-atmosphere mass exchanges are concentrated in the superficial lay3 ers of soils and control most of biological processes required for plant growth.

${ }_{4}$ An accurate description of these layers is of first importance when developing

5 realistic boundary conditions to be implemented in large-scale environmental

6 models. Intensive research has been done to develop efficient numerical mod-

7 els of water transport in the vadose zone. In particular, the quantification of

8 total water evaporation from soil is a crucial issue since it governs the water 9 content dynamics near the surface (Gowing et al., 2006).

$10 \quad$ Following the pioneered work of Philip and de Vries (1957), most of mod11 els have associated the Richard's equation in the liquid phase with a classical 12 diffusive equation in the gas phase while both transport phenomena are coupled through the heat equation (Bittelli et al., 2008; Garcia-Gonzalez et al., 2012; Grifoll et al., 2005; Novak, 2010; Parlange et al., 1998; Saito et al., 2006; Sakai et al., 1999; Thomas and Missoum, 1999; Xiang et al., 2012; 
Yanful and Mousavi, 2003). Although thermal gradients affect liquid water redistribution in soils, the most important coupling process is the transport of latent heat by vapour flux. These models have been successfully used to describe the land-atmosphere water and energy balance of various natural field soils over a large period (Bittelli et al., 2008; Garcia-Gonzalez et al., 2012; Grifoll et al., 2005; Novak, 2010; Saito et al., 2006).

Most of these models have been developed for temperate regions where water content evolves in the capillary domain from saturation to the milting point. Since water vapour flow in semi-arid and arid regions can represent a major part of the overall water flow, it is important to take it into account together with liquid water flow when evaluating hydrologic fluxes (GarciaGonzalez et al., 2012; Sakai et al., 1999). In this framework, classical models have been extrapolated towards low water contents without carefully checking the validity of such formulations. For instance, usual descriptions of the water retention curve can significantly diverge from experimental points at very low water content (Thakur et al., 2006). Correction functions have been proposed without being fully satisfactory. However, as water content goes to very low values, liquid water takes the form of adsorbed layers onto solid surface and does not behave as "free" water. It has been shown that film flows replace conventional capillary flows at low water content, induces a change in the relative permeability description (Tuller and Or, 2002). It is therefore noteworthy to consider that modelling water transport phenomena at low water content calls for a specific description.

In particular, the local equilibrium assumption is extensively used in most of the theoretical models proposed in the literature (Bittelli et al., 2008; 
Garcia-Gonzalez et al., 2012; Grifoll et al., 2005; Novak, 2010; Parlange et al., 1998; Saito et al., 2006; Sakai et al., 1999; Thomas and Missoum, 1999; Xiang et al., 2012; Yamanaka and Yonetani, 1999; Yanful and Mousavi, 2003). This hypothesis governs the liquid/gas mass exchange by assuming that the partial pressure of vapour remains equal to its equilibrium value. It is generally written as an explicit relation between the relative humidity and the hydraulic head. It allows combining liquid and vapour mass balance equations in a single one describing the global soil moisture content. Implicitly, it amounts to consider that the evaporation process is instantaneous in comparison with the other transport phenomena. This should be fairly satisfactory when capillary forces are predominant. Nevertheless, under particular conditions, a volatilization retardation time has been observed (Armstrong et al., 1994; Bénet and Jouanna, 1982; Chammari et al., 2008). In the hygroscopic domain where adsorption phenomena predominate, phase change kinetics is strongly influenced by the thermodynamic state of water and evaporation rate is drastically reduced (Bénet et al., 2009; Lozano et al., 2008). These experimental observations conduced us to reconsider the local equilibrium assumption in order to assess its reliability.

The aim of this contribution is to revisit water transport modelling in the lower range of water content. The prominence of hygroscopic effects leads us to reject the liquid/gas equilibrium assumption. This requires developing a two-equation model by taking into account the phase change kinetics. It means that, in some specific configurations, the characteristic times of the three transport mechanisms considered (liquid flow, vapour diffusion, liquidgas phase change) are of the same order of magnitude. To fulfil this objective, 
a natural soil of Burkina-Faso has been experimentally characterized from independent tests and soil column experiments have been carried out. The comparison of experimental drying kinetics and water content profiles with computational predictions supports the validation of this description. Therefore, the local equilibrium assumption can be discussed based on numerical simulations. In particular, the location of the evaporation front is identified as it propagates from the upper surface towards deeper layers.

\section{Theoretical and numerical modelling of water transfer}

\subsection{Liquid and vapour transfer model}

A natural soil can be idealized by a triphasic porous medium by considering a solid, a liquid and a gaseous phase, while the gaseous phase consists of two components: dry air and water vapour. Theoretical modelling relies on the following assumptions:

- Temperature is uniform and constant. This hypothesis will be validated a posteriori in the last section based on numerical simulations.

- The solid skeleton is undeformable. Assuming a rigid structure is a strong hypothesis since evaporation and dehydration processes in nonconsolidated soils generally lead to global shrinkage. However, we focus our attention on the hygroscopic domain where these effects are negligible.

- The total gas pressure is constant and uniform, since the convective transport in the gas phase is negligible. Actually, it means that the gas permeability is large enough to assume that a pressure gradient will 
be instantaneously equilibrated when compared to the other transport phenomena.

Therefore, three elementary phenomena are considered: liquid filtration governed by capillary and gravity effects, vapour diffusion in the gas phase and liquid-gas phase change of water. Fundamental mass balance equations of water in liquid and gas phase are written:

$$
\begin{array}{r}
\frac{\partial \rho_{l}}{\partial t}+\nabla \cdot\left(\rho_{l} \mathbf{v}_{l}\right)=-\hat{\rho_{v}} \\
\frac{\partial \rho_{v}}{\partial t}+\nabla \cdot \mathbf{J}_{\mathbf{v}}=\hat{\rho_{v}}
\end{array}
$$

where $\rho_{l}$ and $\rho_{v}\left(\mathrm{~kg} \mathrm{~m}^{-3}\right)$ are, respectively, the apparent density of liquid water and its vapour, $\mathbf{v}_{l}\left(\mathrm{~m} \mathrm{~s}^{-1}\right)$ is the intrinsic velocity of liquid water and $\mathbf{J}_{v}\left(\mathrm{~kg} \mathrm{~m}^{-2} \mathrm{~s}^{-1}\right)$ is the vapour diffusion flux. The phase-change rate $\hat{\rho}_{v}$ $\left(\mathrm{kg} \mathrm{m}^{-3} \mathrm{~s}^{-1}\right)$ is thus a volumetric scalar flux, representing the mass of water transforming from a liquid state to a vapour state by unit volume and unit time.

From an experimental point of view, appropriate state variables are the mass water content, $w(\%)$, defined as the ratio between the apparent mass densities of liquid and solid:

$$
w=\frac{\rho_{l}}{\rho_{s}}
$$

and the vapour partial pressure in the gas phase, $p_{v}(\mathrm{~Pa})$, linked to the apparent density of vapour, $\rho_{v}$, through the ideal gas law:

$$
\phi_{g} p_{v}=\frac{R T}{M_{w}} \rho_{v}
$$

where $R\left(\mathrm{~J} \mathrm{~kg}^{-1}\right)$ is the ideal gas constant and $M_{w}(\mathrm{~kg})$ is the molar mass of water. The volume fraction of the gas phase, $\phi_{g}$, is related to the water 
104

content by:

$$
\phi_{g}=\frac{V_{g}}{V}=1-\frac{\rho_{s}}{\rho_{s}^{*}}-w \frac{\rho_{s}}{\rho_{l}^{*}}
$$

where $\rho_{s}^{*}$ and $\rho_{l}^{*}\left(\mathrm{~kg} \mathrm{~m}^{-3}\right)$ are, respectively, the real density of solid and liquid phase.

\subsection{Vapour diffusion}

The vapour diffusion flux, $\mathbf{J}_{v}$, is classically described by a first order Fick's law:

$$
\mathbf{J}_{v}=-D_{v s} \nabla \rho_{v}^{*}
$$

where $D_{v s}$ is the effective vapour diffusion coefficient in the soil. It generally depends on the tortuosity as presented in next section dealing with experimental characterization.

\subsection{Liquid filtration}

The liquid filtration flux appearing in Eq. 1 can be expressed by the Darcy's law extended to the non-saturated case. The validity of such description toward very low water content is questionable since the concept of liquid pressure is meaningless (Baker and Frydman, 2009; Low, 1961; Nitao and Bear, 1996). An alternative proposed by Bénet et al. (2012) is to rely on the chemical potential. Therefore, filtration transport is written:

$$
\rho_{l} \mathbf{v}_{l}=-K\left(\nabla \mu_{l}-\mathbf{g}\right)
$$

where $\mu_{l}\left(\mathrm{~J} \mathrm{~kg}^{-1}\right)$ is the mass chemical potential of liquid water, $\mathbf{g}\left(\mathrm{m} \mathrm{s}^{-2}\right)$ is the gravity acceleration vector. The filtration coefficient, $K$, refers to the soil effective conductivity by means of:

$$
K=K_{r} K_{s a t} \frac{\rho_{l}^{*}}{g}
$$


where $K_{r}$ is the relative permeability function and $K_{\text {sat }}\left(\mathrm{m} \mathrm{s}^{-1}\right)$ the hydraulic conductivity at saturation.

The chemical potential is a function of the water content described by the soil/water retention curve. It is usually built by merging measurements from classical tensiometry and sorption isotherm. Depending on the research area (civil, petrol or food engineering, agronomy, pedology), various names are used to designate this potential (suction, soil matrix potential, capillary pressure, liquid activity). The chemical potential can be seen as a unifying concept well defined in a thermodynamic framework (Job and Hermann, 2006). From its energetic definition, the chemical potential can consistently describe the thermodynamic state of water over the whole range of water content (Bénet et al., 2012).

\subsection{Liquid-gas phase change}

From thermodynamic considerations, it can be shown that the volumetric rate of phase change $\hat{\rho}\left(\mathrm{kg} \mathrm{m}^{-3} \mathrm{~s}^{-1}\right)$ is proportional to the water chemical potential difference between the liquid and vapour states (Bedeaux and Kjelstrup, 2004; Bénet and Jouanna, 1982; Kuiken, 1994). A detailed development of this phase change theoretical relation has been given by Bénet et al. (2009) and the main results are recalled here. In the isothermal case, the non-equilibrium phase change rate is expressed as a function of the vapour partial pressure by:

$$
\hat{\rho_{v}}=-L \frac{R}{M_{w}} \ln \left(\frac{p_{v}}{p_{v e q}}\right)
$$

where $L\left(\mathrm{~kg} \mathrm{~K} \mathrm{~s} \mathrm{~m}^{-5}\right)$ is a phenomenological coefficient to be determined experimentally as detailed in next section. The vapour pressure at equilibrium, 
$p_{v e q}$, is defined as the product of the saturating vapour pressure at the given temperature multiplied by the water activity:

$$
p_{v e q}=a_{w}(w) p_{v s}(T)
$$

The liquid activity is defined by the sorption isotherm curve. Since it is an equilibrium properties, it can only describe an equilibrium situation as required by the local equilibrium assumption. Rejecting this fundamental hypothesis means that the vapour pressure, $p_{v}$, can diverge from its equilibrium value, $p_{v e q}$

\subsection{Numerical discretization}

Finally, mass balance equations are written:

$$
\frac{\partial w}{\partial t}-K_{s a t} \frac{\rho_{e}^{*}}{\rho_{s} g} \nabla \cdot\left(K_{r} \frac{\partial \mu_{l}}{\partial w} \nabla w-K_{r} \mathbf{g}\right)-L \frac{R}{\rho_{s} M_{w}} \ln \left(\frac{p_{v}}{p_{v e q}}\right)=0
$$

$$
\frac{\partial}{\partial t}\left(\phi_{g} p_{v}\right)-\nabla \cdot\left(D_{v s} \nabla p_{v}\right)+L \frac{R^{2} T}{M_{w}^{2}} \ln \left(\frac{p_{v}}{p_{v e q}}\right)=0
$$

These non-linear equations are strongly coupled, on one hand, through the phase change term, $\hat{\rho_{v}}$, and on the other hand, through physical characteristics that depends on the water content: $\phi_{g}(w), D_{v s}(w), L(w)$.

Balance equations are discretized based on finite-volume formulation using a one-dimensional regular mesh where the unknowns, $w$ and $p_{v}$ are located at the centre of grid blocks. A first-order upstream scheme is used to describe the convective term appearing in the liquid mass balance. Temporal integration is performed using a fully implicit scheme to get numerical stability. To handle with non-linearities, a Newton-Raphson method ensures an accurate convergence for a moderate time step. 


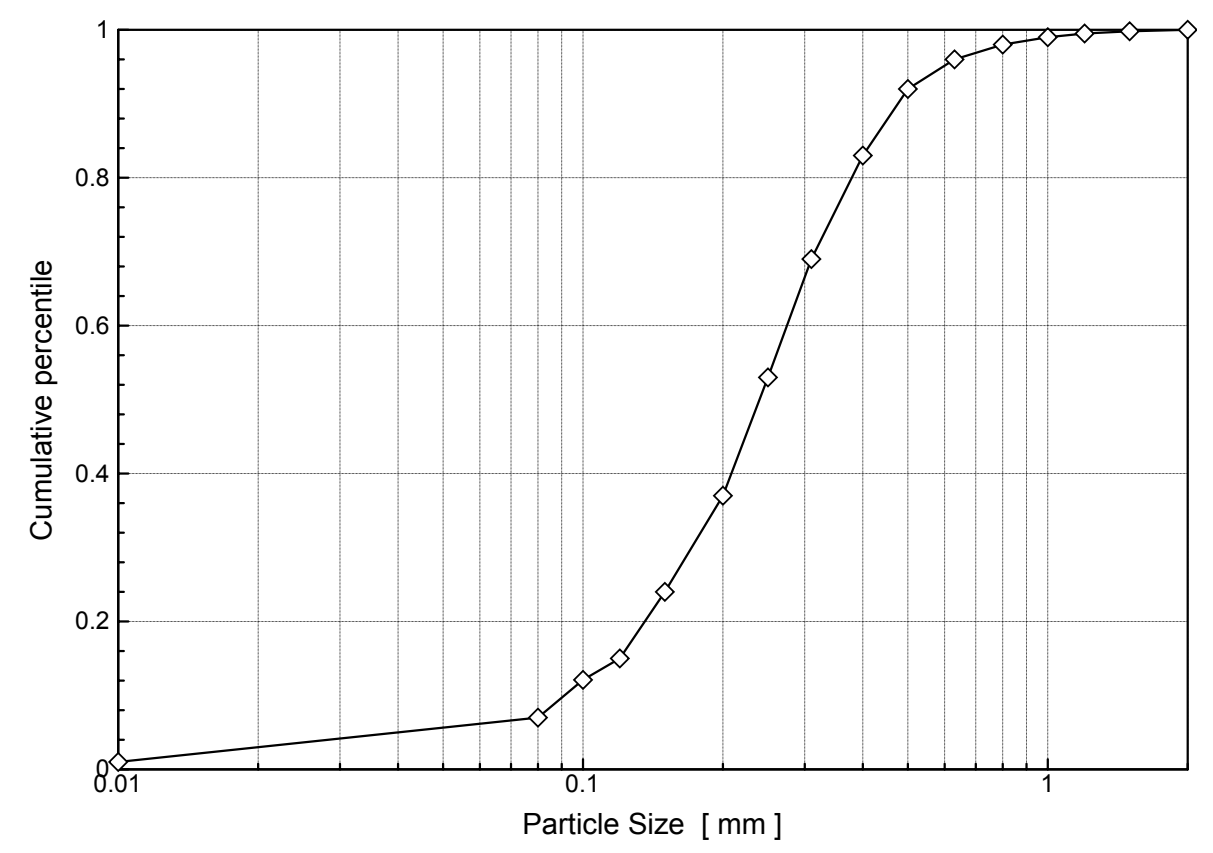

Figure 1: Soil granulometric curve.

3. Materials: a typical soil from Burkina-Faso

The material under investigation is a natural soil from Nasso, BurkinaFaso. From its particle size distribution (Fig. 1), this soil can be classified as a fine sand, the silty or clayey fraction is almost negligible. This is in agreement with the sorption isotherm curve which highlights a limited hygroscopic domain that ranges from $0 \%$ to $2 \%$ (Fig. 2).

\subsection{Vapour diffusion}

Through Fick's equation (Eq. 6), the vapour diffusion flux depends on the effective diffusion coefficient in soil, $D_{v s}$. It is generally defined as:

$$
D_{v s}=\tau \phi_{g} D_{v a}
$$




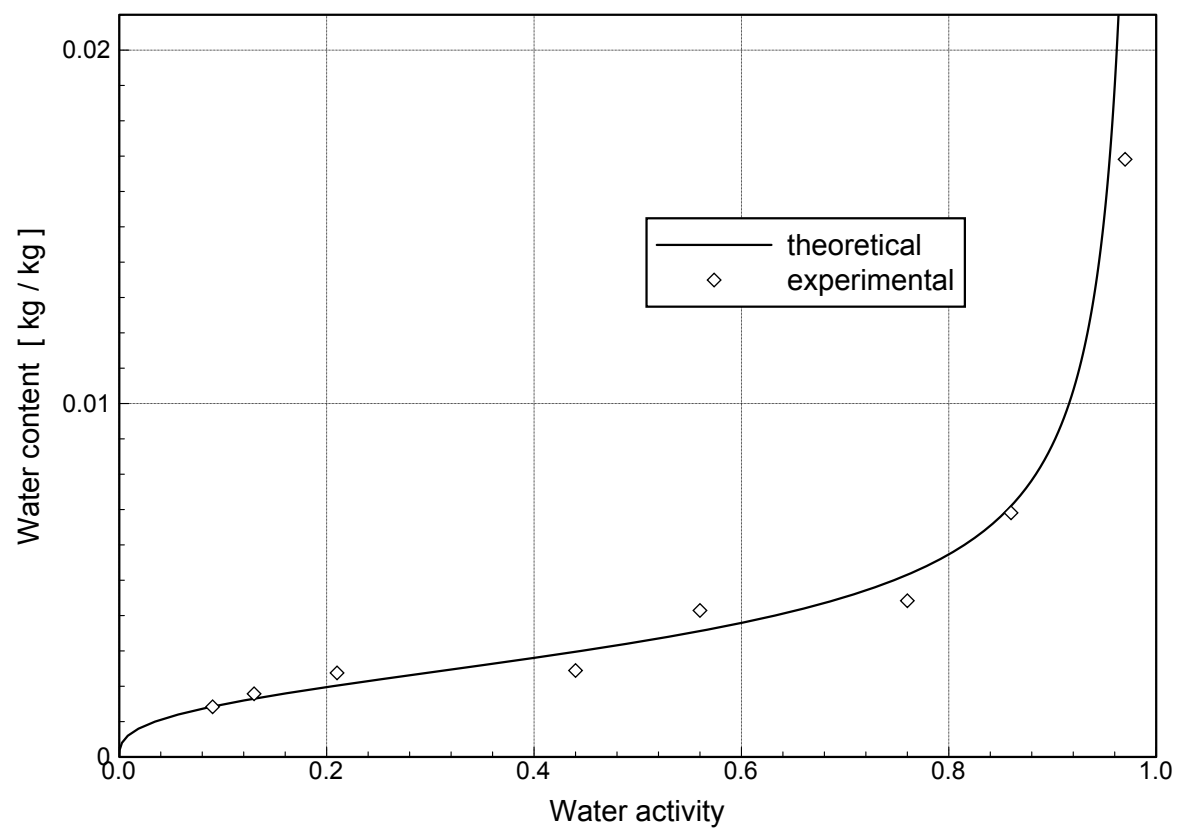

Figure 2: Experimental sorption isotherm curve and theoretical modelling (Fredlund et al., 2002). 
where $\tau$ represents the tortuosity and $D_{v a}$ the free diffusion coefficient of vapour in air. Standard correlation gives a value at $30^{\circ} \mathrm{C}, D_{v a}=26.1 \times$ $10^{-6} \mathrm{~m} \mathrm{~s}^{-2}$ (Campbell, 1985). Several relations have been proposed to describe the tortuosity coefficient as a function soil characteristics (Abu-El-Shar and Abriola, 1997; Moldrup et al., 2000). The classical relation proposed by Millington \& Quirck (Moldrup et al., 2001) has been chosen:

$$
\tau=\phi_{g}^{\frac{7}{3}} / \phi^{2}
$$

Anyway, numerical simulations have brought out a weak dependence of total water transport on the diffusion model. Regarding the case under investigation, the various relations proposed in the literature are roughly equivalent.

\subsection{Liquid filtration}

The soil water retention curve has been determined by merging measures from tensiometry and sorption isotherm. This is based on classical devices such as the pressure plate and standard saline solutions. Relying on both experimental techniques leads to characterize the soil/water equilibrium state over the whole range of water content. As discussed by Bénet et al. (2012), a variety of micro-scale mechanisms governs the soil/water interaction. Describing their macro-scale manifestation by means of pressure head or suction is meaningless in the low water content range. The classical theory based on capillary effects leads to misinterpretations and cannot be extended without careful investigation. Therefore, the chemical potential is more appropriate. Following this point of view, the soil/water retention curve (Fig. 3) is presented with the water mass chemical potential in abscissa. 


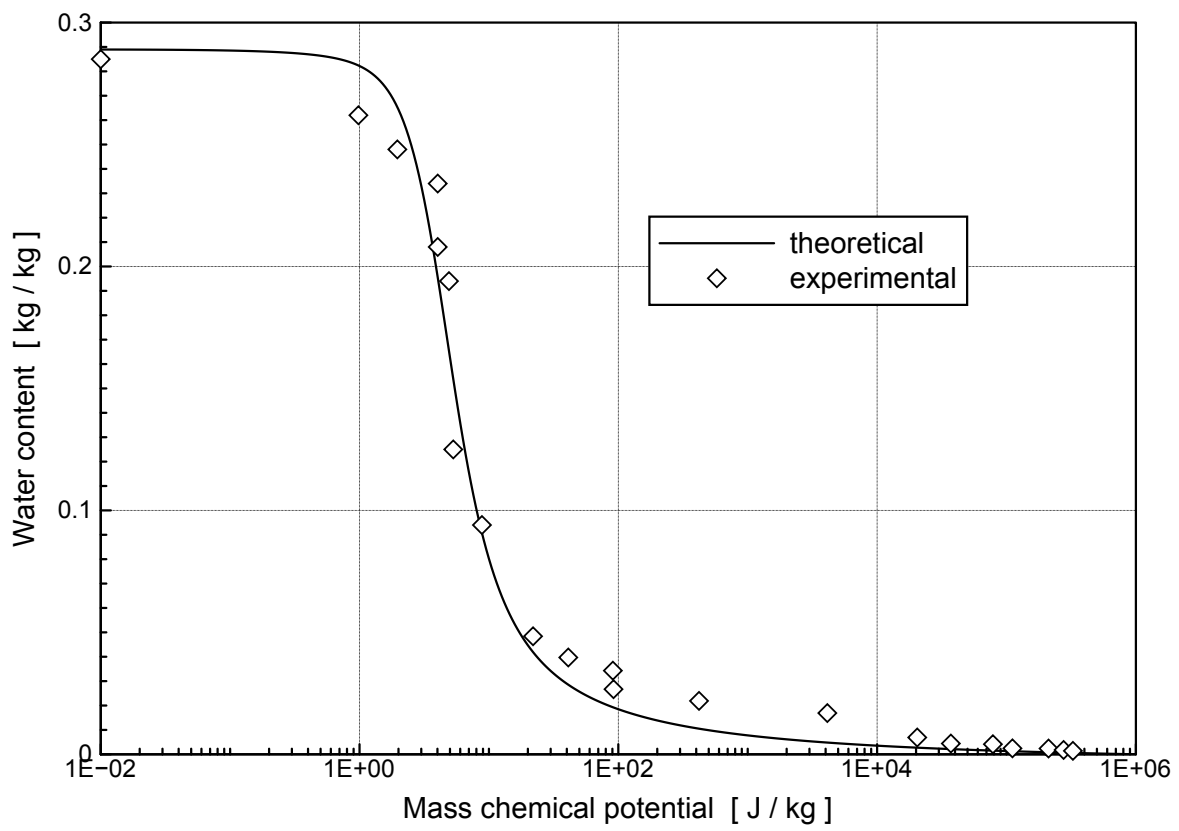

Figure 3: Experimental and fitted theoretical soil water retention curve (Fredlund and Xing, 1994). 
Several models have been presented in the literature to represent the soil/water retention curve. By analysing the behaviour of several soils, Thakur et al. (2006) highlighted that the fitting function proposed by Fredlund and Xing (1994) is the most appropriate description valid for very low water content. This model is given by:

$$
w=\left[1-\frac{\ln \left(1+\frac{\mu}{\mu_{r}}\right)}{\ln \left(1+\frac{10^{6}}{\mu_{r}}\right)}\right] \frac{w_{\text {sat }}}{\left[\ln \left(e+\left(\frac{\mu}{\mu_{i}}\right)^{n}\right)\right]^{m}}
$$

where $\mu_{r}, \alpha, n$ and $m$ are soil parameters. Numerical identification with experimental points lead to values: $\mu_{i}=3.78, \mu_{r}=9.02, n=2.87$ and $m=1.10$, as represented in Fig. 3 .

The hydraulic conductivity at saturation, $K_{\text {sat }}$, was measured experimentally with saturated samples compacted to reach a solid apparent mass density, $\rho_{s}=1500 \mathrm{~kg} \mathrm{~m}^{3}$, which corresponds to a porosity, $\phi=43 \%$. The average value obtained from several trials is: $K_{\text {sat }}=3.995 \times 10^{-6} \mathrm{~m} \mathrm{~s}^{-1}$.

The relative permeability function, $K_{r}$, is assumed to be described by the Mualem's predictive model explicited in the case of the soil/water retention curve proposed by Van Genuchten (1980). The mathematical development leads to the following relation (Van Genuchten and Nielsen, 1985):

$$
K_{r}=\sqrt{S_{e}}\left[1-\left(1-S_{e}^{\frac{1}{m}}\right)^{m}\right]^{2}
$$

where the effective saturation, $S_{e}$, is defined by

$$
S_{e}=\frac{w-w_{r e s}}{w_{s a t}-w_{r e s}}
$$

The water content at saturation, $w_{\text {sat }}$, the residual water content, $w_{\text {res }}$, and the exponent, $m$, are soils characteristic identified on the soil water retention curve (Fig. 3) using the relation proposed by Van Genuchten (1980). 
Parameter values obtained from the numerical identification procedure are: $w_{\text {sat }}=0.289, w_{\text {res }}=0.00942, m=0.526$

\subsection{Liquid-gas phase change}

The phase change coefficient, $L$, introduced in this relation, should depends on the state variables such as the water content, the temperature and on the nature of the soil. This coefficient must be determined experimentally and has been the focus of several works (Lozano et al., 2008, 2009; Ruiz and Bénet, 2001). An original experimental device has been developed to analyse the return back to equilibrium of a soil sample subjected to non-equilibrium conditions. This non-equilibrium situation is caused by, first, extracting the gas phase of the soil sample, and then, replacing it by dry air, what results in a macroscopic thermodynamic non-equilibrium between the liquid phase and its vapour. Thus, the dependence of the phase change coefficient $L$ on several physical variables (temperature, water content, total gas pressure) has been experimentally investigated (Lozano et al., 2009; Ruiz and Bénet, 2001). The influences of the nature of the liquid and of the soil texture have also been underlined.

From a large set of experimental data carried out in isothermal conditions with pure water in clayey silty sand, Lozano et al. (2008) have provided a complete model of the phase change coefficient. Its variations as functions of the water content and the vapour partial pressure are characterised by 3 coefficients $\left(L_{e q}, k, r\right)$ through the following expressions:

$$
\text { close to equilibrium, i.e., } \quad r \leq \frac{p_{v}}{p_{v e q}} \leq 1 \quad: \quad L=L_{e q}
$$


far from equilibrium, i.e., $\quad 0 \leq \frac{p_{v}}{p_{v e q}} \leq r \quad: \quad L=L_{e q}+k\left(r-\frac{p_{v}}{p_{v e q}}\right)$

The neighbourhood of an equilibrium situation, i.e., when the vapour partial pressure is close to its equilibrium value, corresponds to the validity domain of the linear thermodynamics of irreversible processes and a constant phenomenological coefficient is observed. Outside of this domain, i.e., far from equilibrium, an affine dependence on the vapour partial pressure is obtained and the phase change rate is highly increased. Concerning the soil under investigation, the influence of the water content on model parameters $\left(L_{e q}\right.$, $r$ ) is presented in Figs. 4 and 5 while the third parameter $r$ has be found to be fairly constant, $r=0.93$. Some bell-shaped curves are generally observed, where the maximum around $3 \%$ is roughly the upper limit of the hygroscopic domain. Above this maximum, the phase change rate decreases since the liquid-gas interface area reduces. For water content greater than $7 \%$, the gas phase is occluded and phase change cannot be activated. Below the maximum, when hygroscopic effects become predominant, the intensity of solid-liquid interactions increases in the adsorbed layers. The supplementary energy required for water desorption decreases the phase change rate leading to lower values of the coefficient.

\section{Validation: laboratory column experiments}

\subsection{Laboratory column experiments}

Homogenized wet soil was compacted in a PVC tube to reach a solid apparent mass density, $\rho_{s}=1500 \mathrm{~kg} \mathrm{~m}^{3}$, which corresponds to a porosity, $\phi=$ 


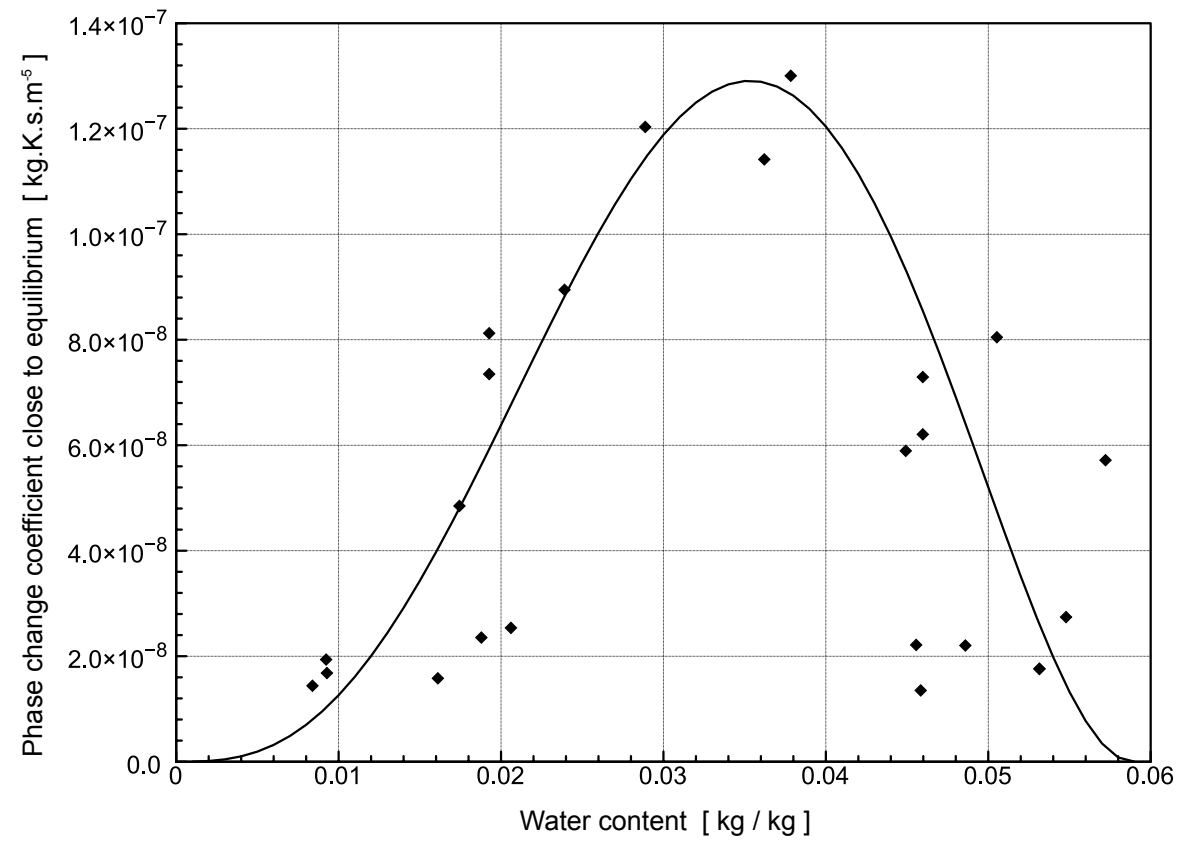

Figure 4: Phenomenological coefficient close to equilibrium, Leq, versus the water content, $w$. Experimental points and fitting relation. 


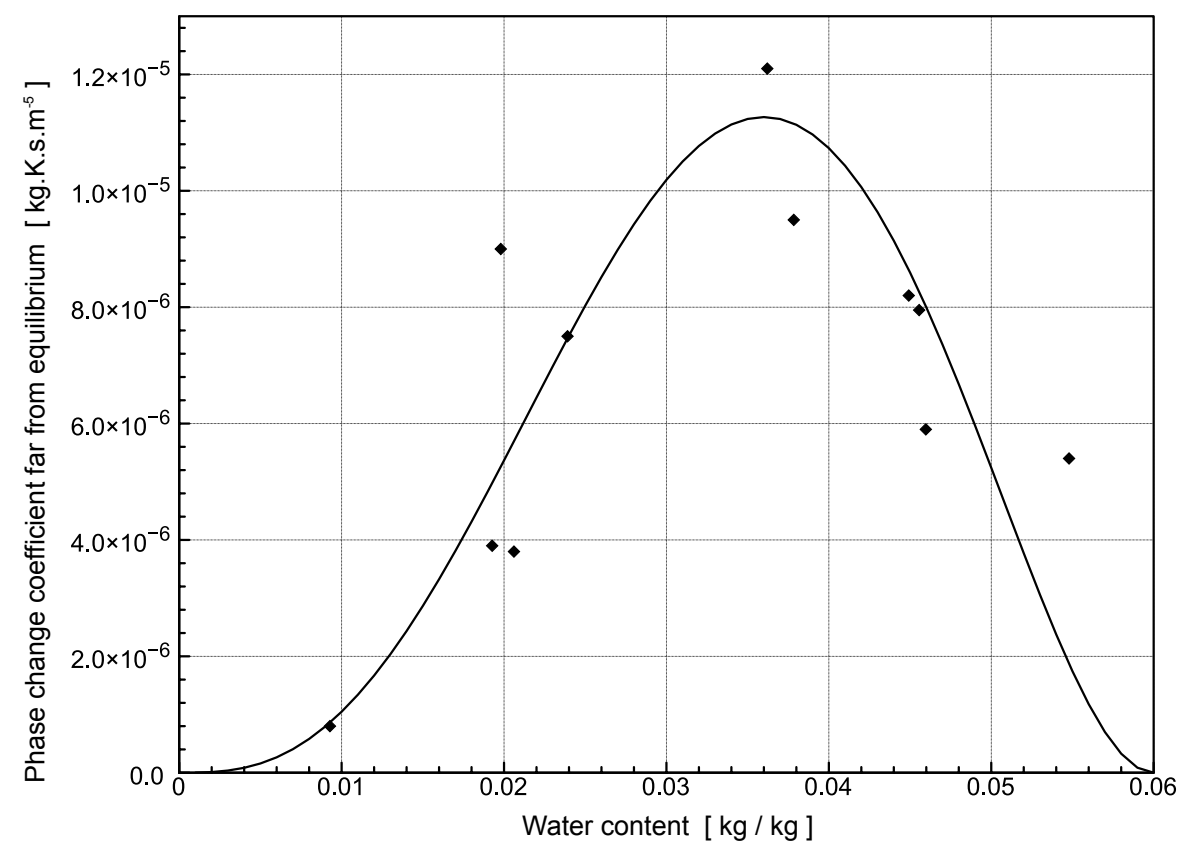

Figure 5: Phenomenological coefficient far from equilibrium, $k$, versus the water content, $w$. Experimental points and fitting relation. 
43\%. Sample dimensions were $30 \mathrm{~cm}$ height and $7.5 \mathrm{~cm}$ diameter. The initial water content of the soil was fixed at $w=6 \%$ to focus on low water content cases. Then, soil samples were placed in a regulated drying atmosphere at controlled temperature $T=30^{\circ} \mathrm{C}$ and relative humidity $R H_{1}=30 \%$ for the first case, and $\mathrm{RH}_{2}=50 \%$ for the second case. The lower surface was hermetically closed while the upper surface was in contact with air.

Columns were weighed at regular time steps to determine the average water content leading to the drying kinetics plotted in Figs. 6 and 7. In each case $\left(R H_{1}=30 \%\right.$ and $\left.R H_{2}=50 \%\right)$, the six experimental kinetics were achieved with a good reproducibility. The determination of water content profiles was based on a destructive method. Indeed, soil columns were cut into $2 \mathrm{~cm}$ slices and water content was measured by differential weighing after 48 hours drying at $105^{\circ} \mathrm{C}$.

The evolutions of water content profiles presented in Figs. 8 and 9 clearly highlight water transport towards the upper side. Surface water content quickly decreases to the residual water content given by the soil/water retention curve (Fig. 3): $w_{\text {res }} \approx 0.01$. At beginning, on can observe that the water content at bottom slightly exceeds the initial water content. This underlines that, in this range of water content, gravitational and capillary forces are of the same order of magnitude.

\subsection{Comparison with theoretical model}

Using identical boundary and initial conditions, numerical simulation of Eqs. 11 and 12 are plotted in solid line on Figs. 6 through 9. A very good agreement between the experimental drying kinetics and theoretical predictions is obtained in both cases (Figs. 6 and 7). Furthermore, numerical sim- 
ulations are able to fairly represent the overall evolutions of water content profiles (Figs. 8 and 9).

Even if the overall agreement is good, some local discrepancies are observed. For instance, at the end of experiments, the gradient of water content is roughly constant what numerical profiles cannot represent. This issue mainly depends on the relative permeability description (Eq. 16) which has not been developed specifically for the soil under investigation. Further experimental characterization is required to completely define the specific relative permeability relation associated with this soil. Anyway, by relying on the literature, the relation chosen in this case seems to be appropriate.

On can notice an evaporation front that penetrates inside the soil column from the top (Rose et al., 2005; Yamanaka and Yonetani, 1999). It corresponds to the propagation of the upper boundary condition through the soil resulting from diffusion and phase change processes. Therefore, a major issue is that the response of soil columns to the imposed relative humidity is adequately represented by our numerical model. Without any fitting parameter, the competition of three phenomena (filtration, diffusion and phase change) is an accurate description of water transport in soils.

\section{Is liquid/gas equilibrium is a valid assumption?}

First of all, the validity of the isothermal assumption can be asserted using numerical simulation. From the numerical results presented in previous section, the heat power consumed by phase change has been computed along the soil column for each time step. At short times ( $t<2$ days), absolute value of the heat power reaches a maximum of $4500 \mathrm{~W} \mathrm{~m}^{-3}$ in the first layer at 


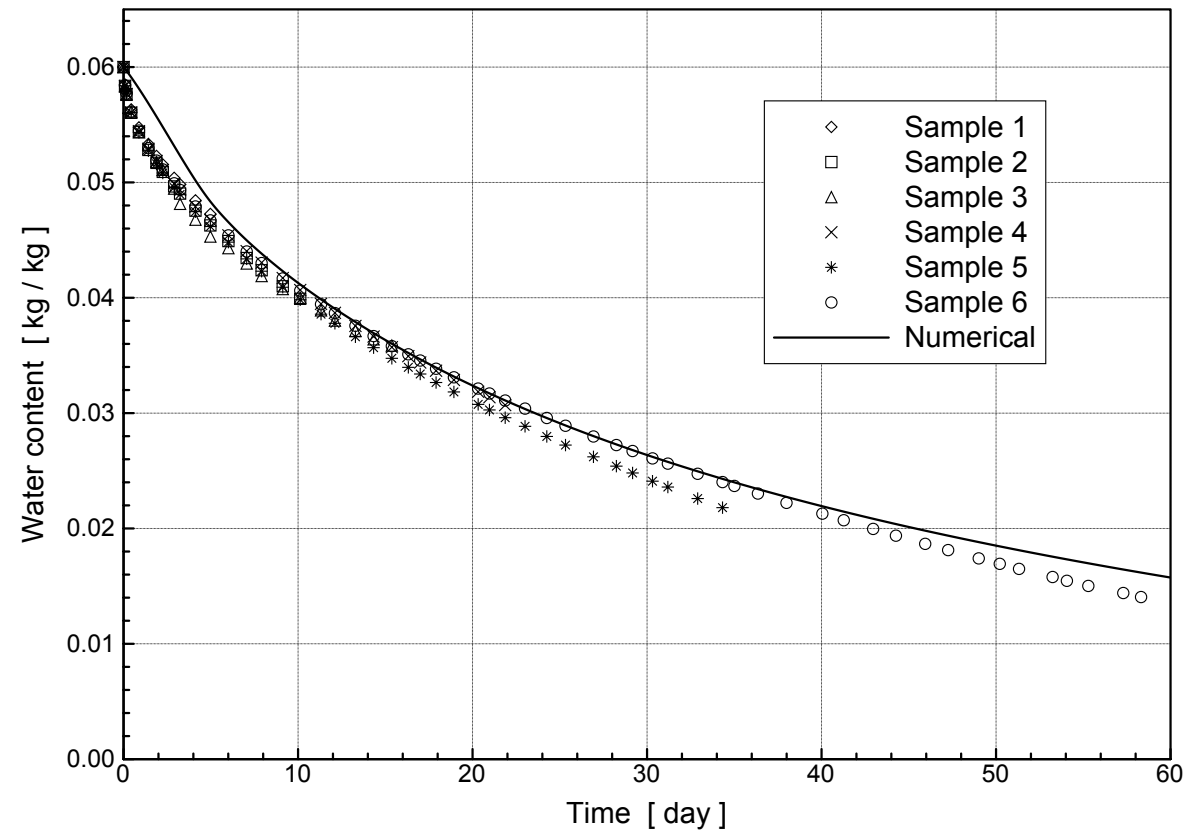

Figure 6: Drying kinetics. Comparison between theoretical prediction and experimental results in the first case: $R H_{1}=30 \%$. 


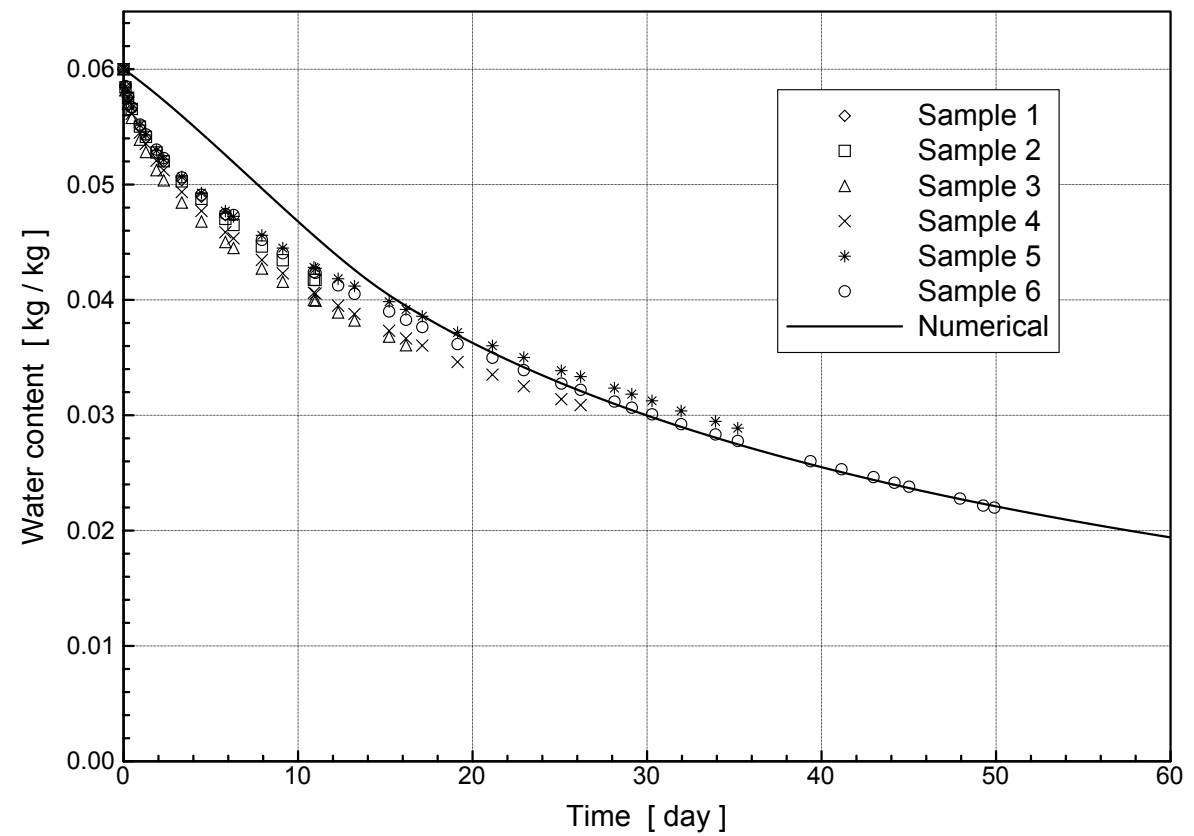

Figure 7: Drying kinetics. Comparison between theoretical prediction and experimental results in the second case: $\mathrm{RH}_{2}=50 \%$. 


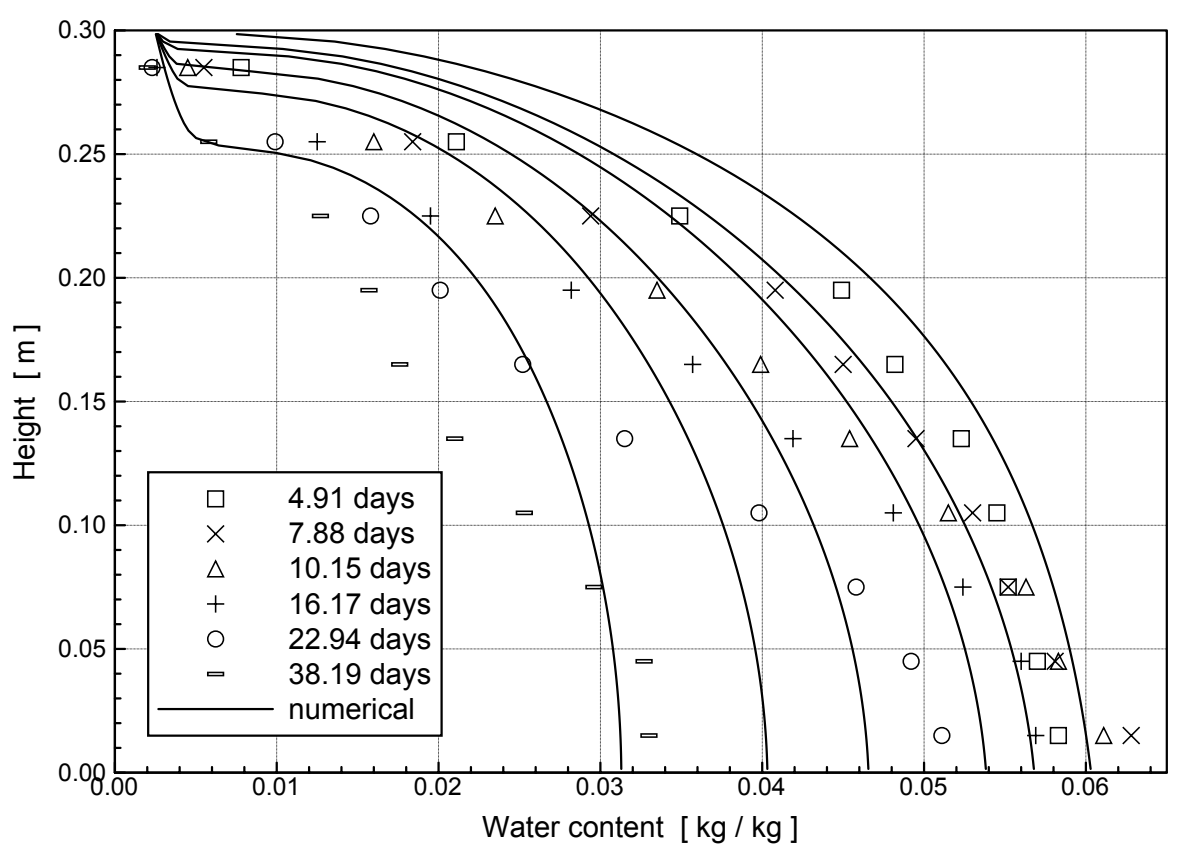

Figure 8: Water content profiles along soil columns. Comparison between theoretical prediction and experimental results in the first case: $R H_{1}=30 \%$. 


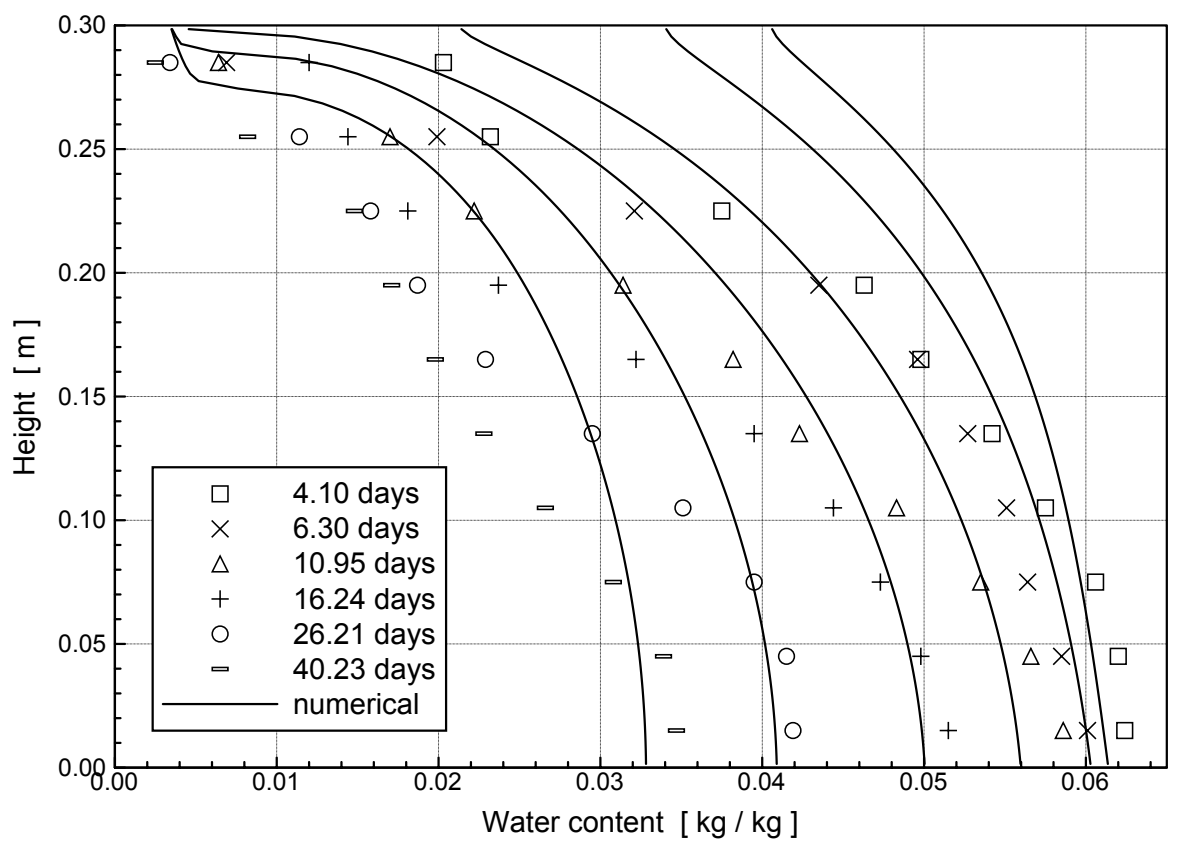

Figure 9: Water content profiles along soil columns. Comparison between theoretical prediction and experimental results in the second case: $\mathrm{RH}_{2}=50 \%$. 
the upper surface. This value quickly decreases below $1000 \mathrm{~W} \mathrm{~m}^{-3}$ reaching $80 \mathrm{~W} \mathrm{~m}^{-3}$ at the end of experiment. Since the heat power is maximal in the first layer of soil in contact with the thermo-regulated atmosphere, small temperature deviations could be observed in the upper part of soil columns in the first 2 days. Temperature gradient would enhance superficial vapour flux and eventually speed up the drying process. This issue could account for the discrepancies observed in drying kinetics at the beginning of experiments (Figs. 6 and 7). Anyway, the heat power computed beyond the first 2 days is not sufficient to generate significant temperature deviations. Indeed, the isothermal assumption is valid as long as the overall drying kinetics is sufficiently slow what is fairly verified in the cases under investigation. Further work is required to couple our model with heat flows and provide a detailed analysis of the isothermal assumption. However, this issue is beyond the scope of this paper.

Most of water (vapour and liquid) transport models developed to describe drying or water management processes relies on the local equilibrium assumption. This hypothesis specifies that, on each point of the domain, liquid and gas phases are in equilibrium. In our case, it can be written as:

$$
\forall t, p_{v}=p_{v e q}
$$

postulating that the vapour pressure remains at its equilibrium value. Physically, it amounts to saying that, when compared to diffusion, phase change processes are sufficiently fast to assume it instantaneous. This usual assumption has been taken into account without carefully checking its domain of validity. A large set of experimental investigations on phase change kinetics have suggested that evaporation in soils may not be as fast as supposed 
(Bénet and Jouanna, 1982; Lozano et al., 2008; Ruiz and Bénet, 2001). For instance, phase change kinetics is drastically decreased when the binding energy of water layers adsorbed on fine-scale grains increased (Lozano et al., 2009). This is mainly the case in the hygroscopic range of water content and is emphasized in the presence of a clayey fraction.

To evaluate the liquid/gas non-equilibrium, the ratio of the vapour pressure divided by its equilibrium value is proposed.

$$
\theta=\frac{p_{v}}{p_{v e q}}
$$

This criterion is plotted along the soil column in Fig. 10. One can note that the vapour pressure can strongly deviate from its equilibrium value. Along the profile, average and largest value of non-equilibrium are given as functions of time in Fig. 11. The short time behaviour $(t<4$ days) corresponds to the establishment of the vapour profile governed by diffusion. It is a transient behaviour which is not of particular interest with regards to the practical applications concerned. For larger time $(t>10$ days $)$, as transport processes are fully established, average non-equilibrium is close to 1 while local values can go up to 0.6 .

Thus, deviation from equilibrium is significant only in a limited region $(0.25<z<0.20)$. To analyse this point, computed water fluxes in liquid and gas phases are shown in Fig. 12. Liquid and gas water fluxes are the 1D representations of, respectively, $\rho_{l} \mathbf{v}_{l}$ in Eq. 1 and $\mathbf{J}_{v}$ in Eq. 2. To compare these fluxes with phase change rate, it has been rewritten in terms of surface flux:

$$
\hat{J}_{v}=\hat{\rho_{v}} d z
$$


where $d z$ is the spatial discretization used in numerical simulation. The intensities of water fluxes and phase change rate cannot be directly compared since they do not take part identically in mass balance equations (Eqs. 11 and 12). Indeed, water fluxes are cumulative through the gradient operator while phase change is a volumetric rate. Nevertheless, the comparison of the three plots supports a qualitative analyse.

Water flux occurs predominantly in liquid phase in the lower part of columns and almost exclusively in gas phase in the upper part (Gowing et al., 2006; Yamanaka and Yonetani, 1999; Yanful and Mousavi, 2003). The switch from one behaviour to the other occurs precisely in the region where non-equilibrium is maximum $(0.25<z<0.20$ in Fig. 10). Since the nonequilibrium criterion corresponds to the generalized thermodynamic force governing the phase change flux (Eq. 9), phase change rate is maximum in this region which creates the main source term in vapour transfer processes. Thus, the 3 water transport phenomena coexist only in this transition zone. As the evaporation front evocated in previous section penetrates in the soil column, this transition zone propagates from the upper boundary condition towards soil bottom. This defines the dry surface layer (DSL) a few centimetres below the surface identified by Yamanaka et al. (1998); Yamanaka and Yonetani (1999). After all, the only manifestation of coupling effects between liquid and vapour transport mechanisms occurs in a limited region as well as the deviation from equilibrium. However, this particular zone governs the overall water transport kinetics. Actually, the cases under investigation underline that the vapour diffusion is not impeded and that there is no specific limiting phenomena. Indeed, the kinetics results from a complex 


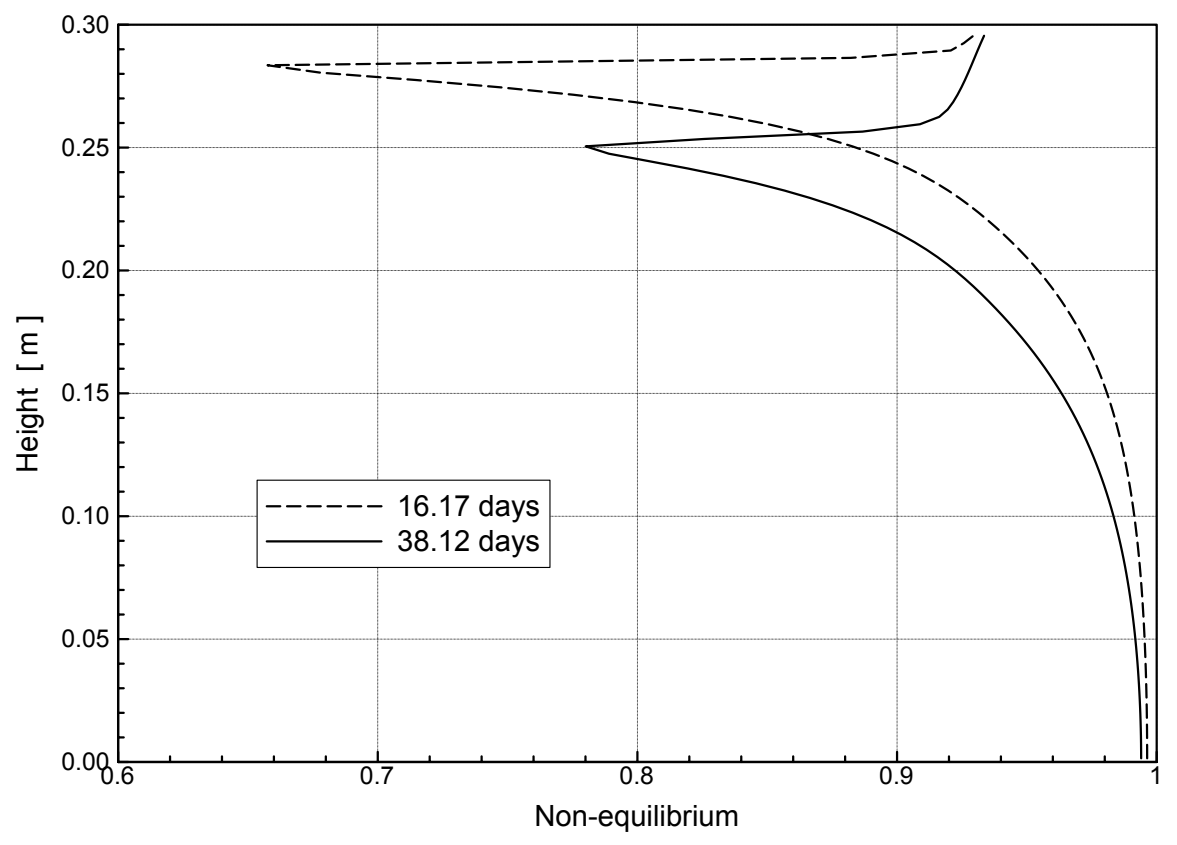

Figure 10: Theoretical liquid/gas non-equilibrium, $\theta=\frac{p_{v}}{p_{v e q}}$, along the soil column in the first case: $R H_{1}=30 \%$ at $t=38.2$ days.

competition of filtration, diffusion and phase change.

Taking into account the liquid/gas equilibrium assumption would lead to artificially increase the phase change rate and enhance the vapour flux. In such a case, the diffusion process would govern the overall kinetics. Since the equilibrium vapour pressure is directly linked to the water content through the sorption isotherm, the vapour diffusive flux would only depend on the water content vertical gradient. This means that a vapour diffusive flux could only occur in the hygroscopic domain where equilibrium vapour pressure deviates from the saturated vapour pressure. From our mind, this constraint is too restrictive while it is usually hidden by the non-isothermal vapour flux.

The material used in this work is a fine sand that does not present im- 


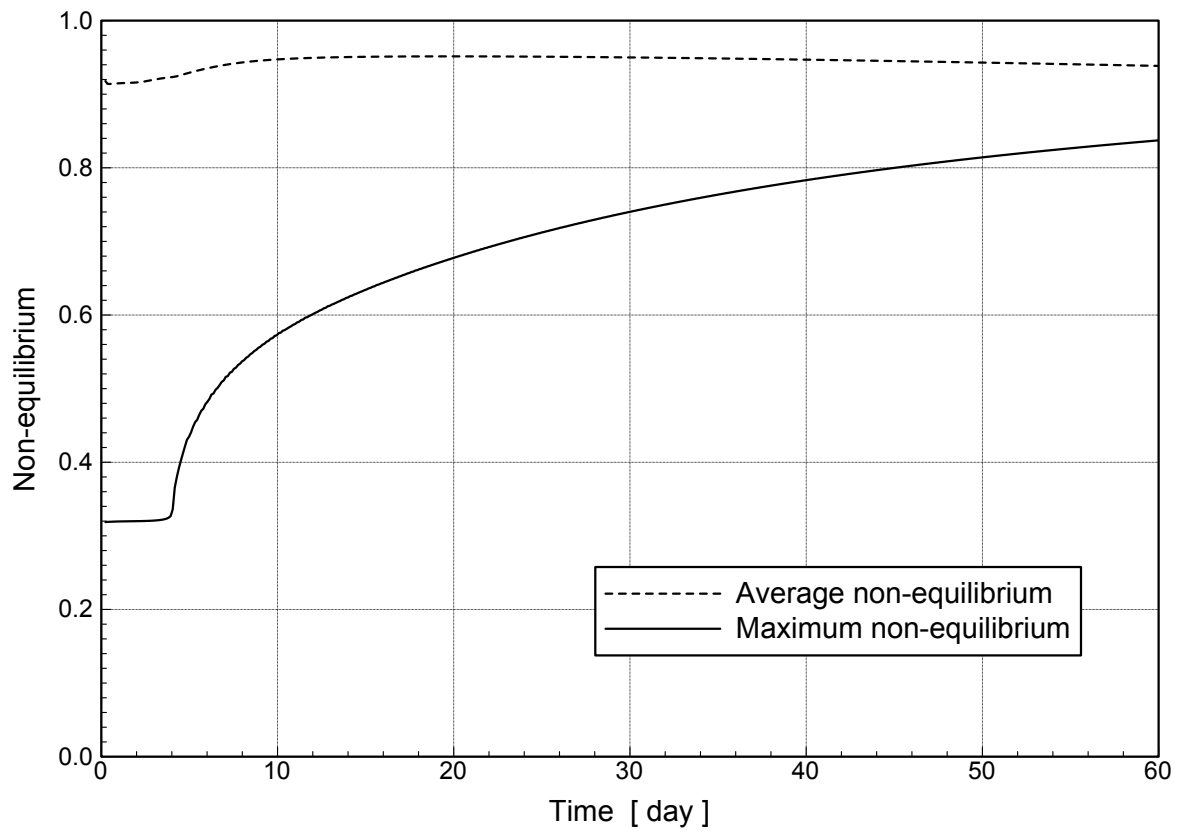

Figure 11: Evolution of maximum and average liquid/gas non-equilibrium, $\theta=\frac{p_{v}}{p_{v e q}}$, as function of time in the first case: $R H_{1}=30 \%$. 


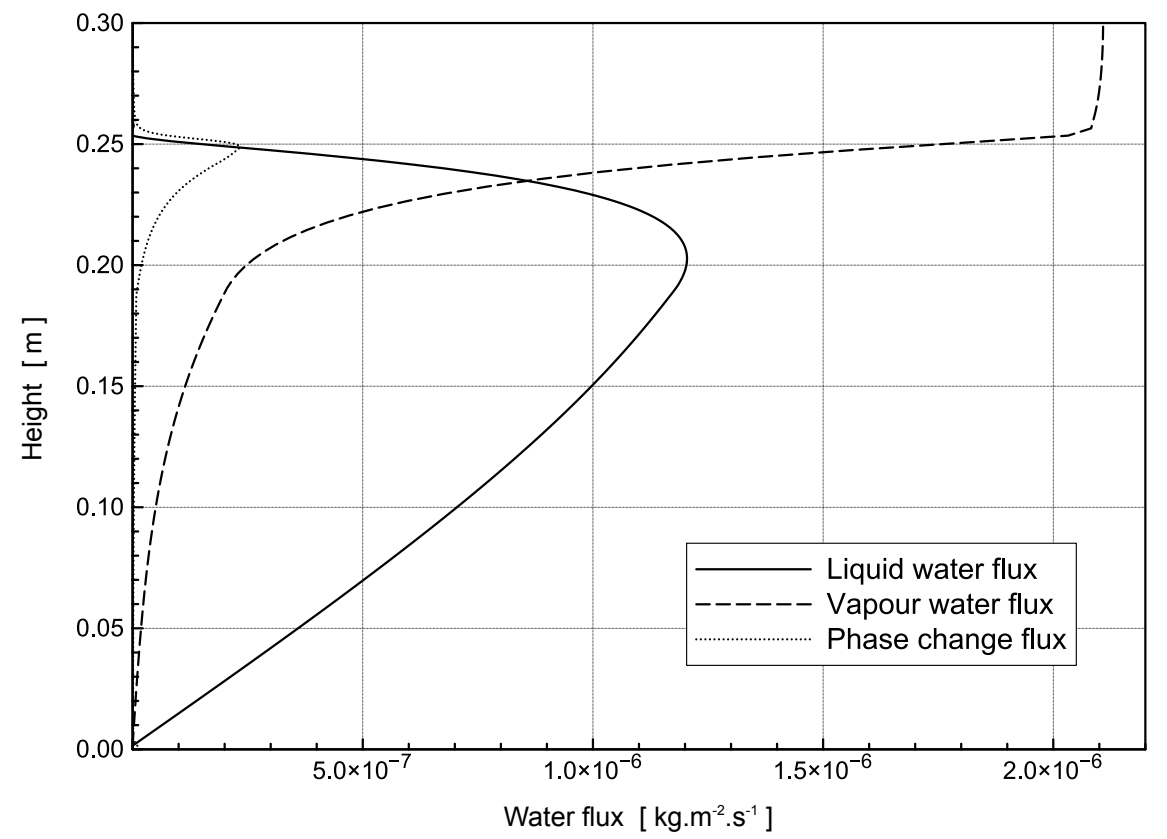

Figure 12: Theoretical water fluxes in gas phase, $\mathbf{J}_{v}$, and liquid phase, $\rho_{l} \mathbf{v}_{l}$, along the soil column in the first case: $R H_{1}=30 \%$ at $t=38.2$ days. The surface representation of phase change rate, $\hat{J}_{v}$ (Eq. 22), is added for comparison. 
portant hygroscopic effects, i.e., the hygroscopic domain represents a limited range of water content $0 \%<w<2 \%$ (Fig. 2). It has been shown that phase change rate is drastically lowered as the water activity deviates from 1 (Bénet et al., 2009). For instance, a small clay fraction $(\approx 10 \%)$ significantly increases hygroscopic effects and decreases phase change kinetics (Lozano et al., 2008). Thus, similar investigations carried out with silty sand or clayey sand would enhance the liquid/gas non-equilibrium calling for a two-equation model such as the one developed in this paper.

\section{Conclusion}

By rejecting the local liquid/gas equilibrium assumption, a non-equilibrium model of isothermal water transport in soil has been proposed. Liquid water and vapour transport are ruled by 2 mass balance equations while the coupling between them is described by a non-equilibrium phase change relation. It amounts to consider that the characteristic times associated with each water transport mechanism (liquid filtration, vapour diffusion, phase change) are of the same order of magnitude. By comparing numerical simulations to drying kinetics and water content profiles obtained from laboratory soil column experiments, a validation of this description is proposed. It must be recalled that the comparison test does not rely on any adjusted parameters since each soil characteristics has been identified with an independent and specific experimental procedure.

In the cases under investigation, local liquid/gas equilibrium can clearly not be a reasonable assumption. Even if average non-equilibrium is not particularly pronounced, it is locally significant as the vapour pressure can 
drop down to half of its equilibrium value. The limited region where a large non-equilibrium is observed defines the evaporation front. It corresponds to the transition from liquid transport in deeper layers to vapour transport in superficial layers which controls the moisture dynamics in bare soils. From this model, the overall evaporation rate can be estimated directly without resorting to empirical correlations (Bittelli et al., 2008; Yanful and Mousavi, 2003).

The more questionable aspect of this model concerns the description of the relative permeability function. Indeed, it is now well established that the relation proposed by Van Genuchten (1980) is not appropriate at low water content. Further investigations are required to develop accurate modelling of liquid flow phenomena at very low water content as proposed by Tuller and Or (2002) and Peters and Durner (2002).

Since the coupling with heat flux is not taken into account, this model cannot be applied directly on practical situations to describe natural field observations. It is rather an heuristic model dedicated to discuss the local equilibrium assumption and assess its eventual reliability. Atmospheric thermal evolutions highly influence water content dynamics in the first layers of bare soils, particularly in arid regions where diurnal temperature variations are large (Gowing et al., 2006). Thus, the approach proposed in this work must be included in a wider modelling such as existing land-surface models (Garcia-Gonzalez et al., 2012; Simunek et al., 2008).

As evidenced previously, phase change kinetics is highly influenced by hygroscopic effects (Lozano et al., 2008). For instance, a clayey fraction will decrease the phase change rate and extend the hygroscopic domain. Such a 
situation would lead to intensify non-equilibrium, or at least to widen the transition zone and the evaporation front. In this framework, the introduction of organic matter like compost should modify the moisture dynamics. Based on this approach, our objective is to revisit the traditional techniques developed in subsaharian regions to prevent from soil evaporation and optimize water resources management.

\section{References}

Abu-El-Shar, W.Y., Abriola., L.M., 1997. Experimental Assessment of Gas Transport Mechanisms in Natural Porous Media: Parameter Evaluation. Water Resources Research 33, 505-516.

Armstrong, J., Frind, E., McClellan, R., 1994. Non-equilibrium mass transfer between the vapor, aqueous, and solid phases in unsaturated soils during vapor extraction. Water Resources Research 30, 355-368.

Baker, R. and Frydman, S., 2009. Unsaturated soil mechanics critical review of physical foundations. Engineering Geology 106, 26-33.

Bedeaux, D., Kjelstrup, S., 2004. Irreversible thermodynamics - A tool to describe phase transitions far from global equilibrium. Chemical Engineering Science 59, 109-118.

Bénet, J.C., Jouanna, P., 1982. Phenomenological relation of phase change of water in a porous medium: experimental verification and measurement of the phenomenological coefficient. International Journal of Heat and Mass Transfer 25, 1747-1754. 
Bénet, J.-C., Lozano, A.-L., Cherblanc, F., Cousin, B., 2009. Phase change of water in hygroscopic porous medium. phenomenological relation and experimental analysis for water in soil. Journal of Non Equilibrium Thermodynodynamics 34, 133-153.

Bénet, J.-C., Ramirez-Martinez, A., Ouedraogo, F., Cherblanc, F., 2012. Measurement of the chemical potential of a liquid in porous media. Journal of Porous Media 15, 1019-1029.

Bittelli, M., Ventura, F., Campbell, G.S., Snyder, R.L., Gallegati, F., Pisa, P.R., 2008. Coupling of heat, water vapor, and liquid water fluxes to compute evaporation in bare soils. Journal of Hydrology 362, 191-205.

Campbell, G. S., 1985. Soil physics with BASIC, Elsevier, New-York.

Chammari, A., Naon, B., Cherblanc, F., Cousin, B., Bénet, J.C., 2008. Interpreting the drying kinetics of a soil using a macroscopic thermodynamic non-equilibrium of water between the liquid and vapour phase. Drying Technology 26, 836-843.

Fredlund, D.G., Xing, A., 1994. Equation for the Soil-Water Characteristic Curve. Canadian Geotechnical Journal 31, 521-532.

Fredlund, M.D., Wilson, G.W., Fredlund, D.G., 2002. Use of the grain-size distribution for estimation of the soil-water characteristic curve. Canadian Geotechnical Journal 39, 1103-1117.

Garcia-Gonzalez, R., Verhoef, A., Vidale, P.L. and Braud, I., 2012. Incorporation of water transport in the JULES land surface model: Implications 
for key soil variables and land surface fluxes. Water Resources Research 48, W05538.

Grifoll, J., Gasto, J.M., Cohen, Y., 2005. Non-isothermal soil water transport and evaporation. Advances in Water Resources 28, 1254-1266.

Gowing, J.W., Konukcu, F., Rose, D.A., 2006. Evaporative flux from a shallow watertable: The influence of a vapour-liquid phase transition. Journal of Hydrology 321, 77-89.

Job, G., Hermann, F., 2006. Chemical potential, a quantity in search of recognition. European Journal of Physics 27, 353-371.

Kuiken, G.D.C., 1994. Thermodynamics for Irreversible Processes. Wiley, Chichester.

Lozano, A.-L., Cherblanc, F., Cousin, B. and Bénet, J.-C., 2008. Experimental study and modelling of the water phase change kinetics in soils. European Journal of Soil Science 59, 939-949.

Lozano, A.-L., Cherblanc, F., Bénet, J.-C., 2009. Water evaporation versus condensation in a hygroscopic soil. Transport in Porous Media 80, 209-222.

Low, P. F., 1961. Concept of total potential in water and its limitations: A critique. Soil Science 91, 303-305.

Moldrup, P., Olesen, T., Gamst, J., Schjønning, P., Yamaguchi, T., Rolston, D. E., 2000. Predicting the gas diffusion coefficient in repacked soil: Waterinduced linear reduction model. Soil Sci. Soc. Am. J. 64, 1588-1594. 
Moldrup, P., Olesen, T., Komatsu, T., Schjønning, P. and Rolston, D. E., 2001. Tortuosity, diffusivity, and permeability in the soil liquid and gaseous phases. Soil Sci. Soc. Am. J. 65, 613-623.

Nitao, J.J., Bear, J., 1996. Potentials and their role in transport in porous media. Water Resources Research 32, 225-250.

Novak, M.D., 2010. Dynamics of the near-surface evaporation zone and corresponding effects on the surface energy balance of a drying bare soil. Agricultural and Forest Meteorology 150, 135-1365.

Parlange, M. B., Cahill, A. T., Nielsen, D. R., Hopmans, J. W., Wendroth, O., 1998. Review of heat and water movement in field soils. Soil \& Tillage Research 47, 5-10.

Peters, A., Durner, W., 2008. A simple model for describing hydraulic conductivity in unsaturated porous media accounting for film and capillary flow. Water Resources Research 44: W11417, doi:10.1029/2008WR007136.

Rose, D.A., Konukcu, F., Gowing, J.W., 2005. Effect of watertable depth on evaporation and salt accumulation from saline groundwater. Australian Journal of Soil Research 43, 565-573.

Ruiz, T., Bénet, J.-C., 2001. Phase change in a heterogeneous medium: comparison between the vaporization of water and heptane in an unsaturated soil at two temperatures. Transport in Porous Media 44, 337-353.

Saito, H., Simunek, J., Mohanty, B.P., 2006. Numerical analysis of coupled water, vapor and heat transport in the vadose zone. Vadose Zone Journal $5,784-800$. 
Sakai, M., Toride, N., Simunek, J., 2009. Water and Vapor Movement with Condensation and Evaporation in a Sandy Column. Soil Science Society of America Journal 73, 707-717.

Simunek, J., van Genuchten, M.T., Sejna, M., 2008. Development and applications of the HYDRUS and STANMOD software packages and related codes. Vadose Zone Journal 7, 587-600.

Thakur, V.K.S., Sreedeep, S., Singh, D.N., 2006. Laboratory investigations on extremely high suction measurements for fine-grained soils. Geotechnical and Geological Engineering 24, 565-578.

Thomas, H.R., Missoum, H., 1999. Three-dimensional coupled heat, moisture and air transfer in a deformable unsaturated soil. International Journal for Numerical Methods in Engineering 44, 919-943.

Tuller, M., Or, D., 2002. Unsaturated Hydraulic Conductivity of Structured Porous Media: A Review of Liquid ConfigurationBased Models. Vadose Zone Journal 1, 14-37.

Van Genuchten, M.T., 1980. A closed-form equation for predicting the hydraulic conductivity of unsaturated soils. Soil Science Society of America Journal 44, 892-898.

Van Genuchten, M.T., Nielse, D.R., 1985. On describing and predicting the hydrualic properties of unsaturated soils. Annales Geophysicae 3, 615-628.

Xiang, L., Yu, Z., Chen, L., Mon, J., Lu, H., 2012. Evaluating coupled water, vapor and heat flows and their influence on moisture dynamics in arid regions. Journal of Hydrologic Engineering 17, 565-577. 
${ }_{552}$ Yamanaka, T., Takeda, A., Shimada, J., 1998. Evaporation beneath the soil 553 surface: some observational evidences and numerical experiments. Hydro$554 \quad$ logical Processes 12, 21932203.

${ }_{555}$ Yamanaka, T., Yonetani, T., 1999. Dynamics of the evaporation zone in dry 556 sandy soils. Journal of Hydrology 217, 135-148.

557 Yanful, E.K., Mousavi, S.M., 2003. Estimating falling rate evaporation from ${ }_{558}$ finite soil columns. The Science for the Total Environment 313, 141-152. 